\title{
Acute epithelial injury in the rat small intestine in vivo is associated with expanded expression of transforming growth factor $\alpha$ and $\beta$
}

\author{
A U Dignass, J L Stow, M W Babyatsky
}

\begin{abstract}
Background-Previous studies have shown the importance of transforming growth factors $\alpha$ and $\beta$ (TGF $\alpha$ and TGF $\beta$ ) in modulating epithelial cell restitution after injury in vitro.

Aim-To investigate the role of the growth factors TGF $\alpha$ and TGF $\beta$ after acute epithelial injury in vivo.

Methods-An in vivo model of phytohaemagglutinin (PHA) induced acute epithelial injury in rat small intestine was used. Epithelial cell turnover was assessed by autoradiography and liquid scintillation counting of thymidine uptake. Expression of TGF $\alpha$ and TGF $\beta$ was assessed by immunohistochemistry.

Results-An expansion of the proliferative compartment and increased turnover of intestinal epithelial cells was seen in rats with PHA induced intestinal epithelial injury. Expression of TGF $\alpha$ and TGF $\beta$ peptides was shown in both the epithelial cell and lamina propria compartment. Different patterns of TGF $\alpha$ and TGF $\beta$ expression were seen, however, within the epithelium of rats with acute intestinal injury compared with untreated controls, while the expression of these peptides within the lamina propria was not changed. Conclusions-These findings suggest that acute intestinal epithelial cell injury in vivo is associated with compensatory changes in expression of TGF $\alpha$ and TGF $\beta$ in the epithelial cell compartment, while the lamina propria does not seem to be significantly affected.

(Gut 1996; 38: 687-693)
\end{abstract}

Keywords: epithelial restitution, proliferation, wound healing, phytohaemagglutinin, lectins, growth factors.

The epithelium of the mammalian small and large intestinal mucosa is comprised of a population of highly dynamic epithelial cells with nearly complete turnover every 24 to 96 hours. ${ }^{12}$ The proliferative compartment of epithelial cells is localised to the crypt and spatially segregated from increasingly differentiated cells present along the vertical axis of the functional villus compartment. The balance of proliferative activity with commitment to differentiation and loss of mature cells from the villus requires exquisite mechanisms to regulate this complex system.

Findings over the past years have shown the ability of the gastrointestinal tract to rapidly re-establish the continuity of the surface epithelium after extensive destruction. ${ }^{3-7}$ The epithelial continuity is re-established in two phases. Firstly, epithelial cells adjacent or just beneath the injured surface migrate into the wound to cover the denuded area, a process that has been termed epithelial restitution and occurs both in vitro and in vivo. ${ }^{3-10}$ This process does not require cell proliferation. Restitution has been seen to occur within minutes to hours in vivo. Finally, epithelial cell proliferation and maturation takes place to replenish the decreased cell pool.

Various growth factors and cytokines have been shown to play an important part in the modulation of epithelial cell proliferation and differentiation. Several of those cytokines have been found to be expressed by constituents of the intestinal mucosa and modulate intestinal epithelial cell populations. Particular interest has been focused on TGF $\alpha$ and TGF $\beta$, which have each been shown to be produced by intestinal epithelial cells in vivo and modulate intestinal epithelial cell function in vitro and in vivo. ${ }^{11-16}$ The two factors have counterbalancing effects on proliferation in vitro. TGF $\alpha$ stimulates proliferation while TGF $\beta$ is a potent inhibitor of proliferation in intestinal epithelial cell lines. In addition to modulation of proliferation, these peptides may also regulate other functional properties of intestinal epithelial cells. Thus, TGF $\alpha$ has been reported to modulate electrolyte and nutrient uptake by enterocytes. In addition to its inhibitory effects on proliferation, TGF $\beta$ seems to play a key part in regulating production of extracellular matrix constituents by intestinal epithelial cells in a manner seen for many other cell types. Furthermore, recent studies in this laboratory have shown that TGF $\alpha$ and TGF $\beta$ play an important part in epithelial cell restitution after injury in an in vitro model of epithelial cell injury. ${ }^{17} 18$

Collectively, the functional properties of these growth regulating peptides could enable them to make a contribution to healing after mucosal injury. Only limited data are available, however, on the role of TGF $\alpha$ and TGF $\beta$ in epithelial injury in vivo. In this study, the role of TGF $\alpha$ and TGF $\beta$ in intestinal epithelial injury in vivo is evaluated. To explore the role of peptide growth factors and the response of the surface epithelium to injury, we sought a model in which epithelial damage is largely independent of associated inflammatory and immune responses. In a modification of previously described techniques acute intestinal epithelial cell injury in the small intestine was 
induced orally by phytohaemagglutinin (PHA) in the form of red kidney bean (Phaseolus vulgaris) extract, ${ }^{19-23}$ and the effects of PHA induced epithelial cell injury on epithelial cell turnover and on the expression of TGF $\alpha$ and TGF $\beta$ were determined.

\section{Methods}

Materials

Radiochemicals were obtained from New England Nuclear, Boston, MA. Human recombinant $\mathrm{TGF} \alpha$, antihuman $\mathrm{TGF} \alpha$, and porcine platelet TGF $\beta_{1}$ were obtained from $R$ and $D$ Systems, Minneapolis, $\mathrm{MN}$; turkey antihuman TGF $\beta$ was purchased from Collaborative Research, Bedford, MA. A polyclonal rabbit antibody (A1/29) raised against a synthetic peptide of TGF $\beta_{1}$ kindly provided as a gift from Celtrix Laboratories, Palo Alto, CA and a monoclonal mouse anti-TGF $\alpha$ antibody obtained commercially from Oncogene Science, Uniondale, NY, were used for immunohistochemical studies. Sprague-Dawley rats (250-400 g) were purchased from Charles River Breeding Laboratories, Wilmington, MA. Red kidney beans (Phaseolus vulgaris) were obtained from a single source (Kennebec Bean, North Vassalboro, ME). PHA extract was prepared from red kidney beans by homogenisation in phosphate buffered saline (PBS) and centrifugation for one hour at $30000 \times g$. The supernatants were filtered through glass wool and nylon gauze (pore size: $50 \mu \mathrm{m}$ ). The concentration of red kidney bean extracts were standardised by determination and adjustment of the protein content of red kidney bean extract per body weight. Two different concentrations of red kidney bean extract given in a standard volume of $4 \mathrm{ml}$ were used: an intermediate dose of $0.15 \mathrm{mg}$ protein $/ \mathrm{g}$ body weight and a high dose of $0.46 \mathrm{mg}$ protein $/ \mathrm{g}$ body weight.

\section{Morphological assessment of PHA treated small intestinal tissue}

Animals used for all studies were maintained in accordance with the guidelines of the Committee on Animals at Harvard Medical School and internal guidelines of the Massachusetts General Hospital. After an overnight fast, Sprague-Dawley rats (250-400 g) were given PHA extract standardised by protein concentration per body weight or a comparable volume of PBS solution via an intragastric feeding tube placed through the mouth into the stomach. Two different concentrations of red kidney bean extract were used: an intermediate dose of $0.15 \mathrm{mg}$ protein/g body weight and a high dose of $0.46 \mathrm{mg}$ protein/g body weight. Rats were killed by ether anaesthesia four and six hours after challenge and the small intestine was dissected. Tissues from the proximal and distal small intestine were fixed in neutral buffered formaldehyde and embedded in paraffin wax. Dewaxed 5-7 $\mu \mathrm{m}$ sections were stained with haematoxylin and eosin.

For electron microscopic analysis tissues from the proximal and distal small intestine were fixed immediately in Karnovsky's fixative and consecutively in $1 \%$ osmium tetroxide in PBS. Tissues were dehydrated in ethanol and embedded in Epon. These sections were mounted on copper grids and viewed on a Phillips CM 10 electron microscope.

\section{Assessment of epithelial cell turnover by autoradiography}

Proliferation was assessed by determination of thymidine uptake into epithelial cells using autoradiography. Rats used for autoradiography received an intraperitoneal injection of $100 \mu \mathrm{Ci}\left[{ }^{3} \mathrm{H}\right]$-thymidine simultaneously with PHA extract given orally. Rats were anaesthetised four and six hours after feeding, the small intestine was dissected, and tissues from the proximal and distal small intestine were fixed in neutral buffered formaldehyde. Tissues were dehydrated in ethanol and embedded in paraffin wax. Serial sections were mounted on poly-L-lysine coated slides. After deparaffinisation in ethanol, slides were coated with autoradiography emulsion NTB-2 (Eastman Kodak, Rochester, NY) and exposed for five to 14 days at $4^{\circ} \mathrm{C}$. Slides were developed using developer D-10 and Kodafix solution (Eastman Kodak, Rochester, NY) as suggested by the manufacturer. Sections were counterstained with haematoxylin and eosin.

\section{Assessment of epithelial cell turnover by liquid scintillation counting of thymidine uptake}

Rats were anaesthetised four or six hours after PHA extract given orally and the small intestines were dissected. Primary rat small intestinal cells were isolated by the method of Weiser. ${ }^{24}$ The recovery of a gradient of cells from crypt to villus was confirmed by measurement of sucrase activity and thymidine incorporation as described originally. ${ }^{24}$ Nine epithelial cell fractions representing a gradient from fully differentiated cells (fraction no 1) to crypt cells (fraction no 9) were obtained. Thymidine incorporation in each fraction was determined by liquid scintillation counting and standardised to the protein concentration in each fraction as determined by the method of Bradford. ${ }^{25}$ Data presented under results represent the mean (SD) values obtained from five different animals.

\section{Immunohistochemical localisation of TGF $\alpha$ and TGF $\beta$ peptide}

Serial sections of paraffin wax embedded proximal and distal small intestinal tissue were mounted on poly-L-lysine coated glass slides. Dewaxed and rehydrated sections were incubated for one hour in $1 \% \mathrm{H}_{2} \mathrm{O}_{2}$ to block endogenous peroxidase activity. Sections were incubated with primary polyclonal rabbit antiTGF $\beta_{1}$ antiserum $(42.5 \mu \mathrm{g} / \mathrm{ml}+3 \%$ bovine serum albumine (BSA)) or a monoclonal mouse anti-TGF $\alpha$ antiserum $(25 \mu \mathrm{g} / \mathrm{ml}+3 \%$ BSA) for 40 hours and 16 hours respectively at $4^{\circ} \mathrm{C}$ in a humidified chamber. Bound primary antibody was localised with the Vectorstain 

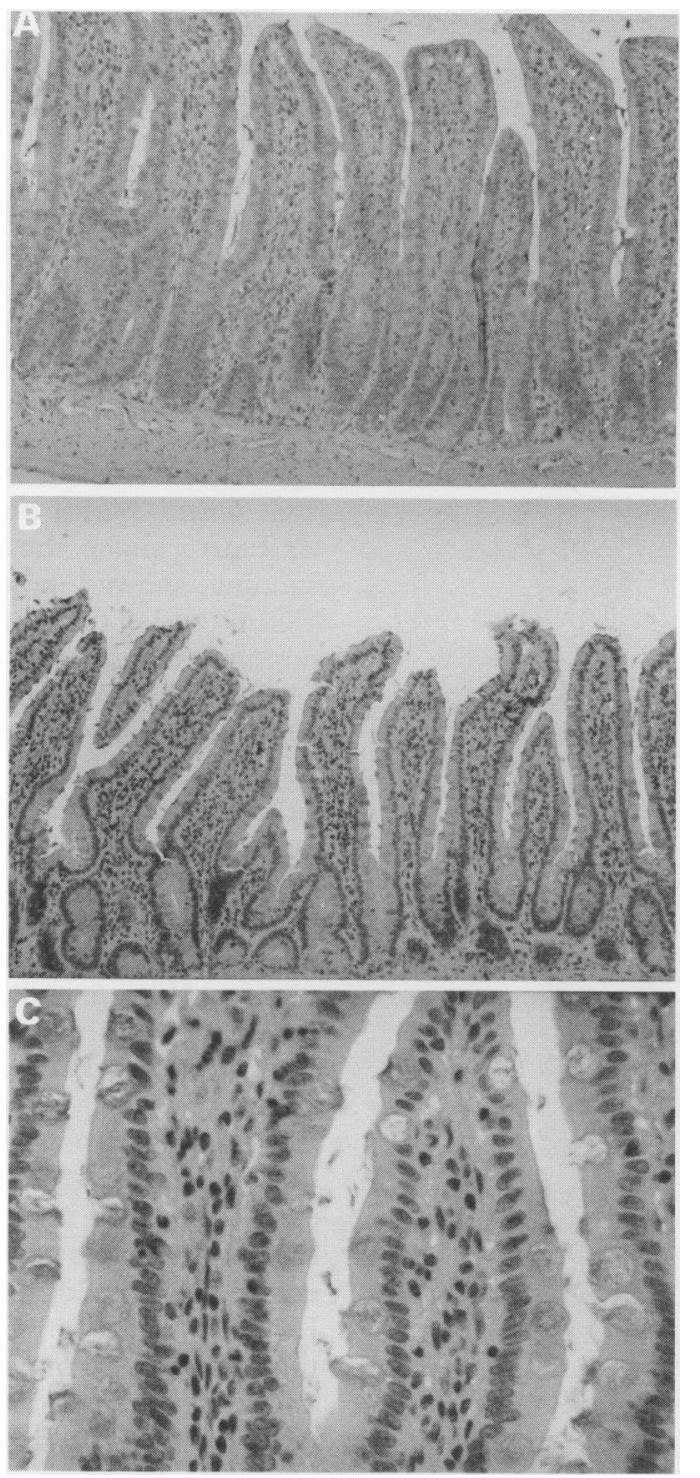

Figure 1: Effects of PHA on small intestinal morphology. Light micrographs of proximal small intestinal tissues collected six hours after rats were challenged with red kidney bean extract $(0.46 \mathrm{mg}$ protein/g body weight) or $P B S$ as detailed under Methods. (A) PBS treated control (magnification, $\times 100)$; (B) PHA treated (magnification, $\times 100)$; (C) PHA treated (magnification, $\times 250$ ).

ABC kit (Vector Laboratories, Burlingame, CA) using diaminobenzidine tetrahydrochloride (DAB) as a substrate according to a protocol suggested by the manufacturer. In control studies, sections were incubated with PBS or pre-immune serum instead of primary antibodies. In addition, the incubation with antiTGF $\beta$ antibody was carried out in the presence of excess porcine TGF $\beta$ and the incubation with anti-TGF $\alpha$ antibody was carried out in the presence of excess human recombinant TGF $\alpha$. No unspecific staining was seen in all of the described controls. Finally, sections were counterstained with haematoxylin and eosin.

\section{Results}

Previous investigators have shown that intestinal epithelial cells in the duodenum and jejunum are disrupted by an acute or chronic challenge with lectins contained in raw red kidney beans. ${ }^{19} 2022232627$ PHA, the lectin contained in uncooked kidney beans, interacts with specific carbohydrate residues and binds with high affinity to microvilli of epithelial cells in the proximal small intestine (duodenum and jejunum) and caecum. ${ }^{26}$ These regions displayed extensive disruption of microvilli after challenge with PHA.

In this study, rats received two different concentrations of red kidney bean extract standardised by protein content of red kidney bean extract per body weight in $4 \mathrm{ml}$ of PBS via an intragastric feeding tube. Tissues from the proximal jejunum and distal ileum were collected four and six hours after intragastric application of PHA and assessed by both light and electron microscopy to evaluate the effect of red kidney bean extract on mucosal morphology. Time points of four and six hours were chosen on the basis of previous work by Weinman $e a^{23}$ showing extensive damage to microvilli two to four hours after challenge with red kidney bean extracts, maximum effects at about six hours after challenge, and nearly normal morphology about 20 hours after challenge showing that damage to epithelium by red kidney bean is self limited and reversible.

As Fig 1 shows, light microscopic analysis of PHA treated small intestinal tissues did not show significant morphological changes compared with untreated rats. Specifically, no inflammation or gross mucosal injury could be detected, and the lamina propria appeared normal. However, electron microscopic studies showed the presence of significant epithelial cell injury. As Fig 2 shows, microvilli of cells at the villus tips are irregular in shape; in comparison with untreated controls shortening, thickening, and partial disruption of microvilli is seen. Furthermore, epithelial cell membrane changes, destruction of organelles, and scattered epithelial cell death are present. These changes were most prominent in epithelial cells at the villus tip, with lesser changes seen in epithelial cells in the lower villus. In contrast, no histological changes were seen within the lamina propria at either the light (Fig 1) or electron microscopy level (data not shown). More severe damage was seen after administration of a higher dose of red kidney bean extract $(0.46 \mathrm{mg}$ protein $/ \mathrm{g}$ body weight) compared with a lower dose of red kidney bean extract $(0 \cdot 15 \mathrm{mg}$ protein/g body weight).

To assess the effect of PHA mediated epithelial cell injury on epithelial cell turnover, in vivo labelling of intestinal epithelial cell proliferation was performed with intraperitoneal injection of $\left[{ }^{3} \mathrm{H}\right]$-thymidine. Primary small intestinal epithelial cells were isolated as sequential populations ranging from fully differentiated villus cells to undifferentiated crypt epithelial cells according to the method of Weiser. ${ }^{24}$ The isolated fractions seemed to be devoid of non-epithelial components by microscopic examination. PHA treatment did not affect the elution process with respect to the number of cells obtained in comparable fractions of untreated and PHA treated animals showing that PHA treatment did not significantly affect the elution process of intestinal 


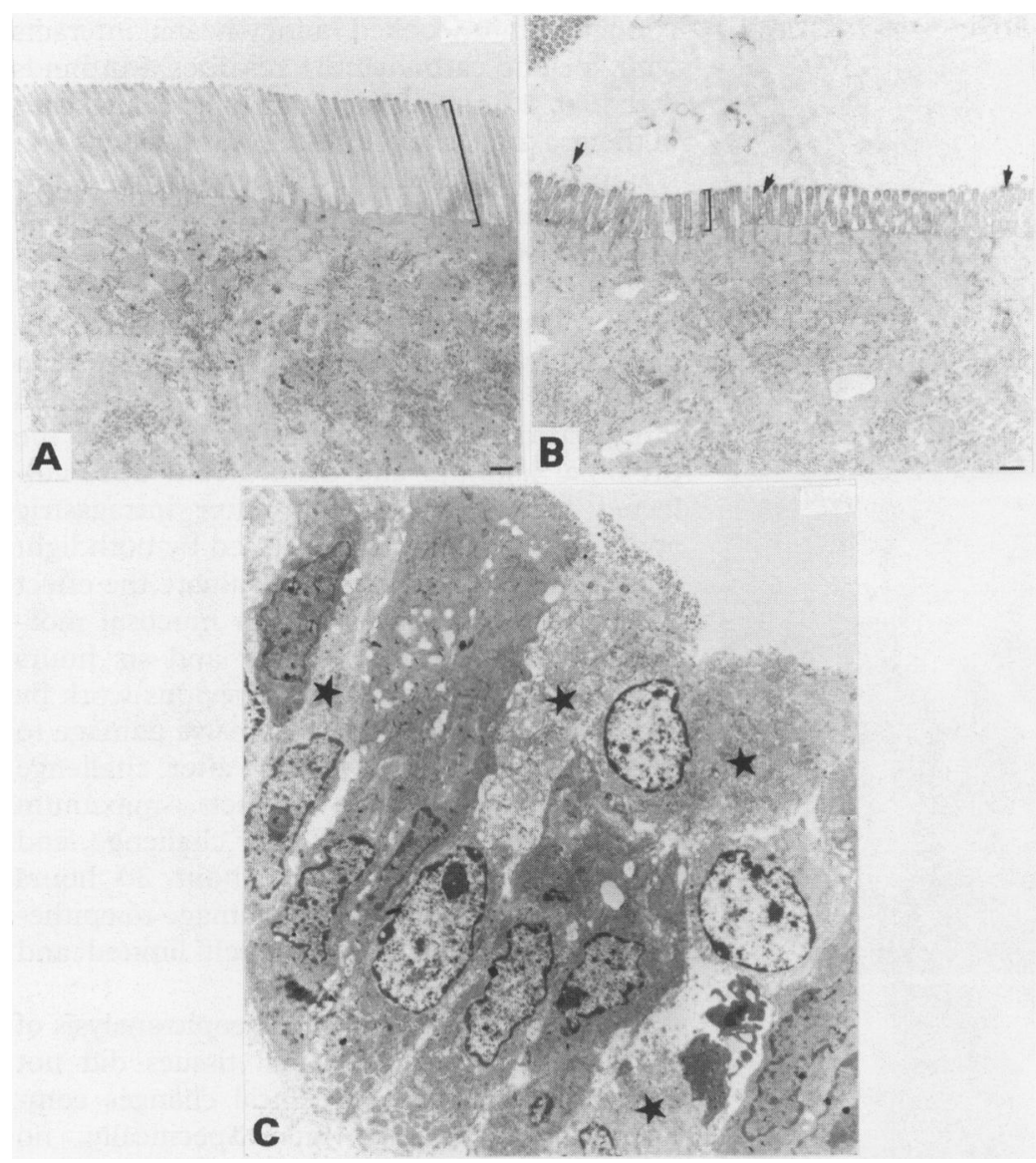

Figure 2: Effects of PHA on rat intestinal epithelial cell fine structure. Electron micrographs of epithelial cells from the tip of the villus, six hours after challenge with red kidney bean extract (0.46 mg protein/g protein); $0.85 \mathrm{~cm}=1.0 \mu \mathrm{m}$. (A) Control; (B) PHA treated, showing the apical brush border. The microvilli are significantly shorter and thicker than controls and there is some dismuption and blebbing of microvillar membranes; (C) PHA treated. Intestinal villi contain some paler cells undergoing cell death (stars). These cells also have grossly disrupted microvilli at their apical brush border.

epithelial cells. Therefore, uptake of $\left[{ }^{3} \mathrm{H}\right]-$ thymidine may serve as a suitable tool to study intestinal epithelial cell turnover in untreated and PHA treated animals. As Fig 3 shows, in untreated rats the uptake of $\left[{ }^{3} \mathrm{H}\right]$-thymidine is essentially confined to fractions containing crypt cells. In contrast, a shift of $\left[{ }^{3} \mathrm{H}\right]$-thymidine uptake towards epithelial cells derived from more distal regions of the villus is seen after the administration of an intermediate dose of red kidney bean extract $(0.15 \mathrm{mg} / \mathrm{g}$ body weight). This shift in the uptake of $\left[{ }^{3} \mathrm{H}\right]-$ thymidine is even more pronounced in rats treated with the higher dose of red kidney bean extract $(0.46 \mathrm{mg}$ protein $/ \mathrm{g}$ body weight $)$ showing an increased turnover of intestinal epithelial cells after PHA administration.

To confirm the impression of an increased turnover of epithelial cells after PHA administration, autoradiography of small intestinal tissues was performed after intraperitoneal injection of $\left[{ }^{3} \mathrm{H}\right]$-thymidine. Proliferating epithelial cells are identified by uptake of $\left[{ }^{3} \mathrm{H}\right]-$ thymidine, detected by black grains over the cell nuclei. As Fig 4 shows, incorporation of $\left[{ }^{3} \mathrm{H}\right]$-thymidine in intestinal mucosa of control rats is limited to epithelial cells located in the basal crypt region. In contrast, in PHA treated rats uptake of the radioactive label can be seen in the upper crypt and lower villus epithelial cells, while no uptake of label can be seen in the basal crypt region confirming the impression that PHA leads to increased turnover and migration of epithelial cells in the small intestine.

The growth factors $\mathrm{TGF} \alpha$ and $\mathrm{TGF} \beta$, which are produced by primary intestinal epithelial cells and modulate epithelial cell function in vitro and in vivo, ${ }^{11-16}$ have recently been found to play an important part in the modulation of intestinal epithelial injury in an in vitro model. ${ }^{1718}$ To assess the expression of TGF $\alpha$ and TGF $\beta$ in association with intestinal epithelial injury in vivo, the distribution of TGF $\alpha$ and TGF $\beta$ peptides were determined. As Figs 5 and 6 show, immunohistochemical staining showed predominant expression of TGF $\alpha$ and TGF $\beta$ within the epithelial cell population and lesser expression in cells of the lamina propria. Expression of $\mathrm{TGF} \alpha$ and TGF $\beta$ peptides in lamina propria cell populations was not affected by PHA administration. In contrast, the expression of these growth factors was changed in the epithelial cell population after exposure to the lectin.

The most abundant expression of TGF $\alpha$ and TGF $\beta$ peptides was seen in epithelial cell populations (Figs 5 and 6). Nevertheless, significant expression of both peptides could be detected within lamina propria cell populations (macrophages, lymphocytes, eosinophils). As Fig 5 shows, strongest staining for TGF $\alpha$ peptide was seen in epithelial cells at the villus tips extending to the mid-villus region in untreated rats. Staining was either absent or very weak in epithelial cells located in the crypt region. Diffusely scattered weak staining could be seen throughout the lamina propria cell populations. TGF $\beta$ peptide was most abundant in epithelial

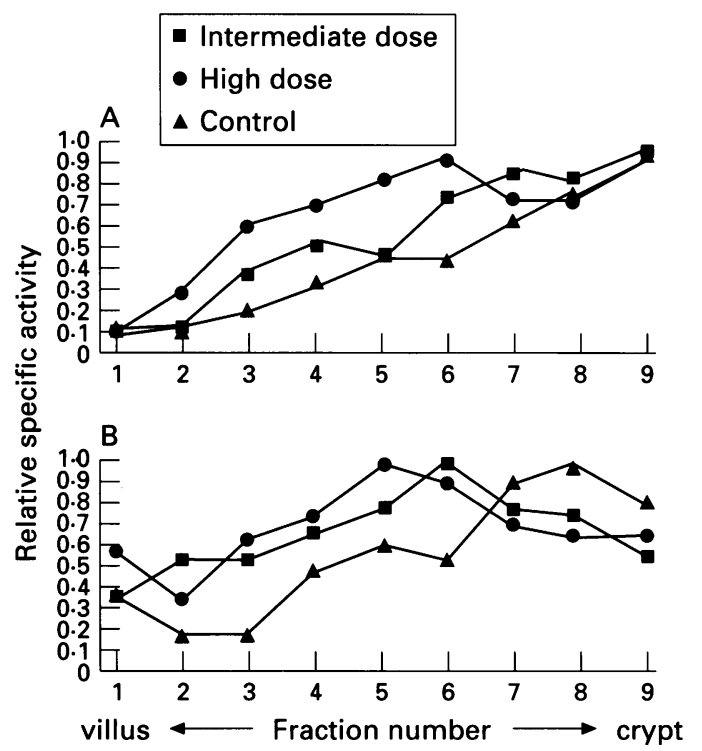

Figure 3: Effects of red kidney bean extracts on rat small intestinal epithelial cell turnover. One hundred $\mu \mathrm{Ci}$ of $\left.{ }^{3} \mathrm{H}\right]$-thymidine was injected intraperitoneally and villus-crypt gradients of isolated small intestinal epithelial cells were obtained four and six hours after challenge with red kidney bean extract as described under Methods. The specific activity of $\left.{ }^{3} \mathrm{H}\right]$-thymidine incorporation (counts per minute per mg of protein) determined for the acid insoluble fraction of each isolated cell fraction is plotted against the cell fractions. (A) Four hours after challenge with red kidney bean extract and injection of

$\left.{ }^{\beta} H\right]$-thymidine; $(B)$ six hours after challenge with red kidney bean extract and injection of $\left.{ }^{\beta} H\right]$-thymidine. 

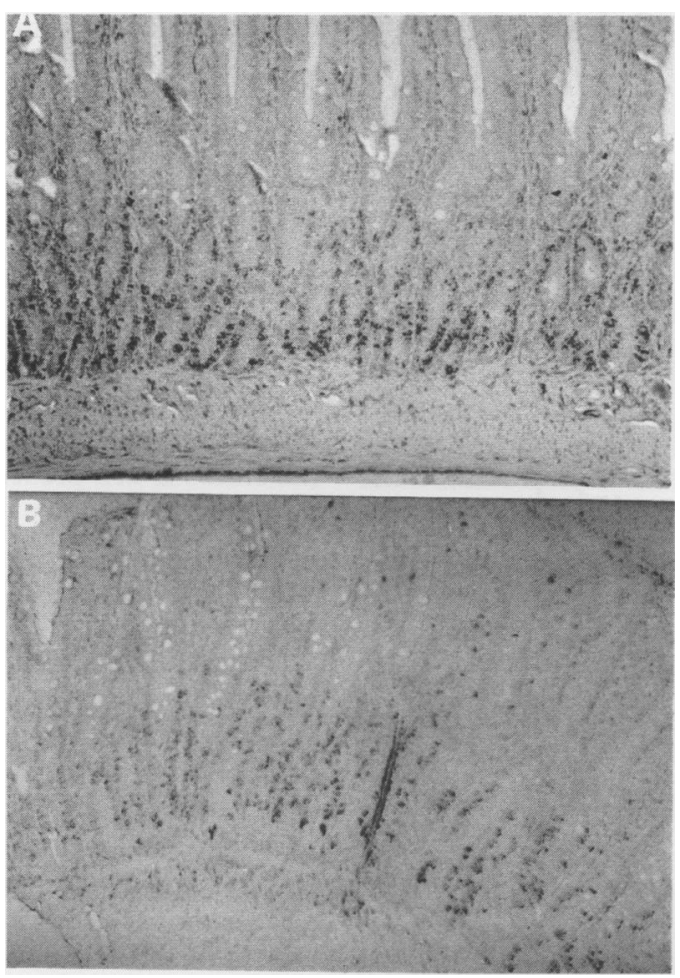

Figure 4: Effects of PHA on the proliferative zone in rat small intestinal epithelium. Autoradiographs of proximal small intestine six hours after rats were challenged with red kidney bean extract $(0.46 \mathrm{mg}$ protein/g body weight) and simultaneous injection of $100 \mu \mathrm{Ci} \beta \mathrm{H}]$-thymidine.

Sections were exposed to autoradiography emulsion and developed as described under Methods. (A) Untreated control. Epithelial cell proliferation is limited to epithelial cells located in the basal crypt region; (B) PHA treated rats. The zone of thymidine uptake has shifted to epithelial cells of the upper crypt and lower villus region.

cells of the upper crypt region in untreated rats (Fig 6). Weaker staining for TGF $\beta$ was seen in epithelial cells located in the lower crypt and villus compartment and significant staining could be detected in non-epithelial cell populations of the lamina propria, especially at the villus tips. In contrast, PHA treated rats showed increased staining for TGF $\alpha$ in epithelial cells of the upper crypt region extending to epithelial cells of the mid-villus region, while strongest staining for TGF $\beta$ was seen in epithelial cells from the upper crypt region to the villus tip (Figs 5 and 6).

\section{Discussion}

Recent studies in this laboratory have shown that several cytokines and growth factors that are expressed in the gastrointestinal tract play an important part in epithelial cell restitution after injury in an in vitro model of epithelial cell injury. ${ }^{171828}$ An increase in epithelial cell restitution in vitro was mediated through a TGF $\beta$ dependent pathway. Only limited information is available on the role of cytokines and peptide growth factors in epithelial cell restitution in vivo. Among the numerous growth factors and cytokines that have been identified within the intestinal mucosa, TGF $\alpha$ and $\beta$ play a pivotal part in the modulation of intestinal epithelial cell function in vitro and in vivo. ${ }^{11-16}$ The two factors contribute to regulation of epithelial cell proliferation, seeming to exert counterbalancing effects on intestinal epithelial cells. While TGF $\alpha$ stimulates intestinal epithelial proliferation, TGF $\beta$ is a potent inhibitor of intestinal epithelial cell proliferation.

Studies to evaluate the effect of these two peptide growth factors on intestinal epithelial cell restitution in vivo are hampered by the lack of animal models that selectively injure epithelial cells without involvement of lamina propria cell populations. To evaluate the participation of the peptide growth factors $\mathrm{TGF} \alpha$ and TGF $\beta$ in intestinal epithelial cell injury, we used a model of PHA induced epithelial cell injury and assessed the expression of TGF $\alpha$ and TGF $\beta$ peptides in vivo.

PHA binds to microvilli of absorptive intestinal epithelial cells along the villus from its tip to the crypt/villus junction but not to microvilli of the undifferentiated cells within the crypt. ${ }^{26}$ Repeated challenge with raw red kidney beans induces damage to intestinal epithelial cells in the rat, which includes vesiculation and shortening of microvilli in the duodenum and jejunum resulting in impaired nutrition, inhibition of growth, and ultimate death. ${ }^{19} 2022$ In contrast, after a single challenge with raw red kidney beans, microvilli show extensive vesiculation along the length of the villi two to four hours after challenge, significant reduction in length six hours after challenge, and nearly normal length about 20 hours after challenge, suggesting that damage to microvilli is self limited and reversible. ${ }^{23}$
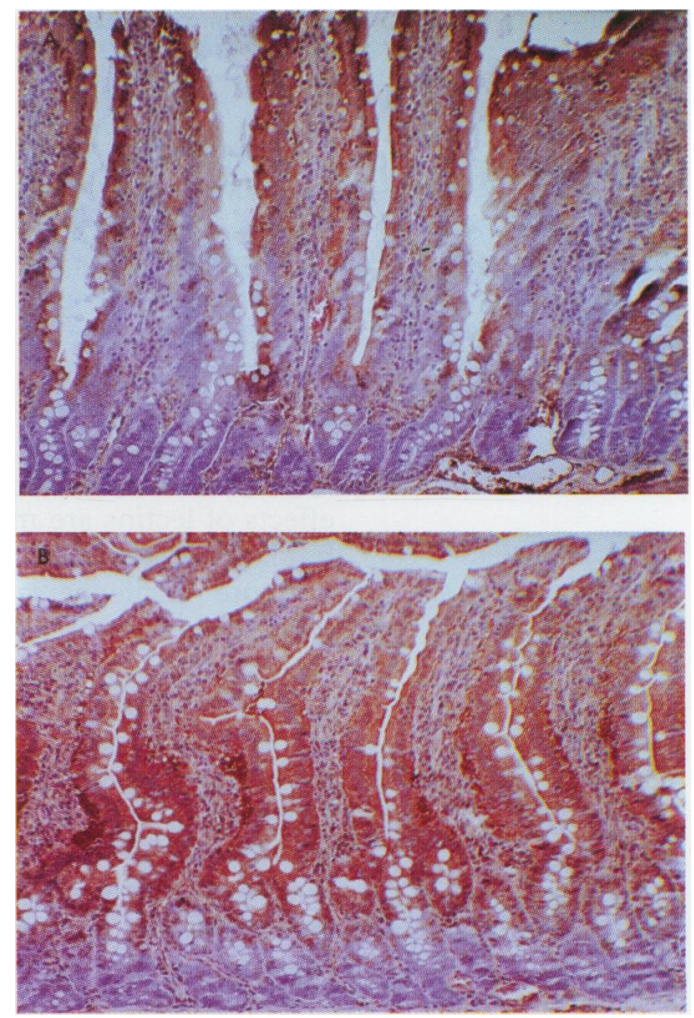

Figure 5: Expression of TGFa peptide in rat proximal small intestinal mucosa. Immunohistochemistry of the small intestine was performed with a monoclonal mouse anti-TGF $\alpha$ antiserum $(25 \mu \mathrm{g} / \mathrm{ml}$ ) as described under Methods. (A) Untreated control. Antibody specific binding was visualised using a peroxidase based staining technique (Vectorstain). Strongest staining is present in epithelial cells located on the villus tips (magnification, $\times 200$ ); (B) PHA treated. Strongest staining can be seen in epithelial cells of the upper crypt region (magnification, $\times 200$ ). 

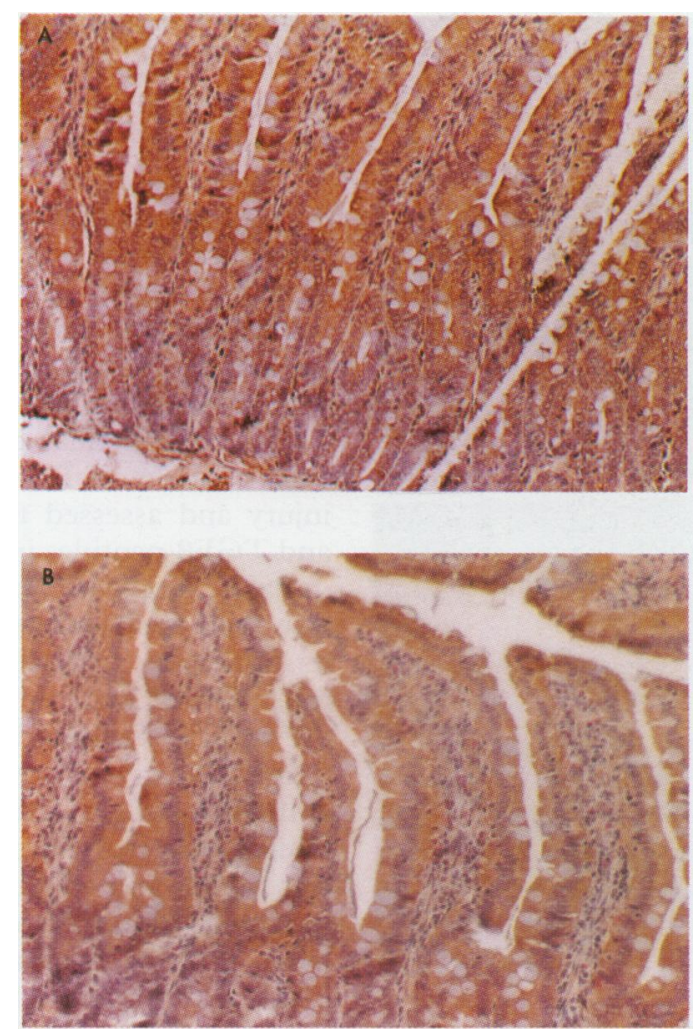

Figure 6: Localisation of TGF $\beta$ peptide expression in rat small intestinal mucosa. Immunohistochemistry of proximal small intestine was performed as outlined under Methods. (A) Untreated control. Tissues were incubated with a primary polyclonal rabbit anti-TGF $\beta$ antiserum

$(42 \cdot 5 \mu g / \mu l)$ as described under Methods. TGF $\beta$ expression is identified as a brownish colour with strongest expression in the upper crypt region (magnification, $\times 200$ ); (B) PHA treated. Strongest staining identified as a brownish colour is seen in epithelial cells extending from the villus tips to the upper crypt region (magnification, $\times 200$ ).

Other lectins including concanavalin $\mathrm{A}$ and wheat germ agglutinin can also injure the mammalian intestine. ${ }^{29} 30$ It has been shown that lectins bind to the glycocalyx of duodenal and jejunal microvilli and that some of these dietary constituents are endocytosed into ribosomal pathways within both absorptive and secretory gut cells. ${ }^{31}$ Deleterious effects of lectins can be prevented by concomitant addition of the appropriate hapten sugar suggesting that toxic effects of lectins are mediated through specific binding to microvilli structures.

Acute challenge with high doses of red kidney bean extract caused a significant and reproducible reduction in the length of microvilli along the length of the villi as previously described. ${ }^{23}$ Intestinal damage seemed to be limited to the epithelial mucosa as assessed by light microscopic and electron microscopic studies. Nevertheless, participation of intraepithelial lymphocytes and of other non-epithelial constituents of the intestinal mucosa cannot be excluded by these techniques. It should be noted that PHA is known to be a potent mitogen for lymphocytes and inducer of lymphocyte transformation. ${ }^{32}$ It may therefore not be possible to discriminate entirely between direct epithelial cell damage or indirect effects resulting from PHA stimulation of other cell populations. However, PHA lectins have been shown in vitro to interact specifically with the human colon carcinoma cell line Caco-2, a model cell line for the study of differentiated enterocytes. ${ }^{33}$ Significant damage to the microvilli of Caco- 2 cells treated with PHA lectins was seen, showing that PHA can directly induce cell damage in intestinal epithelial cells. ${ }^{33}$ The PHA induced epithelial cell damage may provide a useful model system for studies on the modulation of intestinal epithelial cell injury and repair by various regulatory peptides expressed within the intestine. Compared with other models of intestinal inflammation, structural features of the intestinal mucosa are preserved and involvement of non-epithelial cells seems to be at most limited. This model may be more physiologically relevant than models associated with extensive intestinal damage throughout the full thickness of intestine, for example, acetic acid injury.

In vivo labelling of intestinal epithelial cell proliferation with $\left[{ }^{3} \mathrm{H}\right]$-thymidine and subsequent analysis by liquid scintillation counting of isolated primary intestinal epithelial cells as well as autoradiography studies showed an expansion of the proliferative compartment and increased turnover of intestinal epithelial cells in the small intestines of PHA treated rats. These findings contrast with previous observations, ${ }^{23}$ which did not show an acceleration in the rate of cell migration after challenge with red kidney bean extract. This difference might reflect the higher concentrations of red kidney bean extract that were used in this study to induce epithelial cell damage. Stimulation of epithelial cell turnover was most pronounced in animals receiving the highest concentration of red kidney bean extract.

To assess the effects of intestinal epithelial injury on TGF $\alpha$ and TGF $\beta$ in vivo, the expression and localisation of these factors were determined by immunohistochemistry. In untreated rats, strongest staining for TGF $\alpha$ peptide was seen in epithelial cells at the villus tips extending to the mid-villus region and for TGF $\beta$ in epithelial cells of the upper crypt region. In contrast, PHA treated rats showed increased staining for TGF $\alpha$ in epithelial cells of the upper crypt region while strongest staining for TGF $\beta$ was seen in epithelial cells in an area extending from the upper crypt region to the villus tip.

These findings suggest that acute epithelial injury in vivo may result in compensatory changes of TGF $\alpha$ and TGF $\beta$ expression, which could modulate the intestinal response to injury in vivo. TGF $\alpha$ is known to be a potent stimulator of epithelial cell proliferation and highest concentrations of TGF $\alpha$ peptide in the crypt region in PHA treated rats could contribute to the expansion of the proliferative compartment and increase epithelial cell turnover. TGF $\beta$ peptide in PHA treated rats is most abundant in epithelial cells of the villus tips, where the most severe damage of epithelial cells after exposure to lectins can be shown. ${ }^{19} 202326$ Recent work in our laboratory had shown that TGF $\beta$ plays an important part in intestinal epithelial restitution in vitro. 171828 The presence of increased concentrations of TGF $\beta$ peptide at the site of the 
most severe injury may show that TGF $\beta$ also plays an important part in intestinal epithelial restitution in vivo.

These findings show that TGF $\alpha$ and TGF $\beta$ play a part in the modulation of intestinal epithelial cell injury in a model of acute intestinal epithelial cell injury. The PHA model may serve as a valuable tool for studies on the modulation of epithelial cell injury and repair by various regulatory peptides expressed within the intestine. Nevertheless, further studies are necessary to evaluate this model to fully exploit its advantages and possibilities. It has to be emphasised that this model assessed the effects of acute cell damage. We are studying the initial changes of the peptide growth factors $\mathrm{TGF} \alpha$ and $\mathrm{TGF} \beta$ in the course of intestinal epithelial injury and intestinal epithelial wound healing (that is, epithelial restitution). Different responses may have to be expected in more chronic models of inflammation and injury, for example, longterm administration of PHA and in more delayed phases of intestinal wound healing.

These findings show that PHA induced epithelial cell injury induces changes in the expression of the growth factors $T G F \alpha$ and TGF $\beta$ suggesting that these factors might participate in the modulation of epithelial cell function after intestinal epithelial cell injury.

This work was supported by grants from the National Institutes of Health (DK 41557, DK 43351) and the Deutsche Forschungsgemeinschaft (Di 477/1-1). The authors thank Dr Daniel K Podolsky for discussion suggesting the utility of th PHA model, for providing support for the reported studies and for discussion of the manuscript.

Parts of this work have been published previously in abstract form (Gastroenterology 1993; 104: A617).

1 Potten CS, Kellet M, Roberts SA, Rew DA, Wilson GD. Measurement of in vivo proliferation in human colorecta mucosa using bromodeoxyuridine. Gut 1992; 33: 71-8.

2 Lipkin M, Sherlock P, Bell B. Cell proliferation kinetics in the gastrointestinal tract of man. II. Cell renewal in stomach, ileum, colon and rectum. Gastroenterology 1963 45: 721-9.

3 Morris GP, Wallace JL. The roles of ethanol and of acid in the production of gastric mucosal erosions in rats. Virchows Arch B 1981; 38: 23-38.

4 Feil W, Wentzl E, Vattay P, Starlinger M, Sogukoglu R, Schiessel R. Repair of rabbit duodenal mucosa after acid injury in vivo and in vitro. Gastroenterology 1987; 92: 1973-86.

5 Waller DA, Thomas NW, Self TJ. Epithelial restitution in the large intestine of the rat following insult with bile salts. Virchows Arch A 1988; 414: 77-81.

6 Silen W. Gastric mucosal defense and repair. In: Johnson LR, ed. Physiology of the gastrointestinal tract. Vol 2. 2nd ed. New York: Raven, 1987: 1044-69.

7 Lacy ER. Epithelial restitution in the gastrointestinal tract. f Clin Gastroenterol 1988; 10 (suppl 1): 72-7.

8 Nusrat A, Delp C, Madara J. Intestinal epithelial restitution. $\mathfrak{f}$ Clin Invest 1992; 89: 1501-11.

9 Rutten MJ, Ito S. Morphology and electrophysiology of guinea pig gastric mucosal repair in vitro. Am $\mathcal{F}$ Physiol 1983; 244: G171-82.

10 Moore R, Carlson S, Madara JL. Rapid barrier restitution in an in vitro model of intestinal epithelial injury. Lab Invest 1989; 60: 237-44.
11 Suemori S, Ciacci C, Podolsky DK. Regulation of transforming growth factor expression in rat intestinal epithelial cell lines. $\mathcal{f}$ Clin Invest 1991; 87: 2216-21.

12 Kurokawa M, Lynch K, Podolsky DK. Effects of growth factors on an intestinal epithelial cell line; transforming growth factor $\beta$ inhibits proliferation and stimulates differentiation. Biochem Biophys Res Commun 1987; 142: 775-82.

13 Barnard JA, Beauchamp RD, Coffey RJ, Moses HL. Regulation of intestinal epithelial cell growth by transforming growth factor $\beta$. Proc Natl Acad Sci USA 1989;
86: 1578-82.

4 Barnard JA, Polk WH, Moses HL, Coffey RJ. Production of transforming growth factor a by normal rat small intestine. transforming growth factor a by norma

15 Thomas DM, Nasim MM, Gullick WY, Alison MR Immunoreactivity of transforming growth factor alpha in the normal gastrointestinal tract. Gut 1992; 33: 628-31

16 Yasui W, Ji ZQ, Kuniyasu H, Ayhan A, Yokozaki H, Ito H, Tahara E. Expression of transforming growth factor alpha in human tissues: immunohistochemical study and Northern blot analysis. Virchows Arch $A$ 1992; 421: 513-9.

17 Ciacci C, Lind SE, Podolsky DK. Transforming growth factor $\beta$ regulation of migration in wounded rat intestinal epithelial monolayers. Gastroenterology 1993; 105: 93-101.

18 Dignass AU, Podolsky DK. Cytokine modulation of intestinal epithelial restitution: central role of transforming growth factor $\beta$. Gastroenterology 1993; 105: 1323-32.

19 King TP, Pusztai A, Clarke EMW. Kidney bean (Phaseolus vulgaris) lectin-induced lesions in rat small intestine: 1 . Light microscope studies. F Comp Pathol 1980; 90: 585-95.

20 King TP, Pusztai A, Clarke EMW. Kidney Bean (Phaseolus vulgaris) Lectin-induced lesions in rat small intestine: 3. Ultrastructural studies. $\mathcal{F}$ Comp Pathol 1982; 92: 357-73.

21 Banwell JG, Boldt DH, Meyers J, Weber FL, Miller B, Howard R. Phytohemagglutinin derived from red kidney bean (Phaseolus vulgaris): a cause for intestinal malabbean (Phaseolus vulgaris): a cause for intestinal malab-
sorption associated with bacterial overgrowth in the rat. Gastroenterology 1983; 84: 506-15.

22 Rossi MA, Mancini Filho J, Lajolo FM. Jejunal ultrastructural changes induced by kidney bean (Phaseolus vulgaris) lectins in rats. Brf Exp Pathol 1984; 65: 117-23.

23 Weinman MD, Allan $\mathrm{CH}$, Trier JS, Hagen SJ. Repair of microvilli in the rat small intestine after damage with lectins contained in the red kidney bean. Gastroenterology 1989; 97: 1193-204.

24 Weiser MM. Intestinal epithelial surface membrane glycoprotein synthesis: an indicator of cellular differentiation. f Biol Chem 1973; 248: 2536-41.

25 Bradford MM. A rapid and sensitive method for the quantitation of microgram quantities of protein ultilizing the tation of microgram quantities of protein ultilizing the principle

26 King TP, Pusztai A, Clarke EMW. Immunocytochemical localization of ingested kidney bean (Phaseolus vulgaris) lectins in rat gut. Histochem $\mathcal{F} 1980 ; 12: 201-8$.

27 Kik MFL, Koninkx JFJG, van den Muysenberg A Hendriksen F. Pathological effects of phaseolus vulgaris isolectins on pig jejunal mucosa in organ culture. Gut 1991; 32: 886-92.

28 Dignass AU, Tsunekawa S, Podolsky DK. Fibroblast growth factors modulate intestinal epithelial cell growth and migration. Gastroenterology 1994; 106: 1254-62.

29 Lorenzsonn V, Olsen WA. In vivo responses of rat intestinal epithelium to intraluminal dietary lectins. Gastroenterology epithelium to intra

30 Sjolander A, Magnusson K-E, Latkovic S. Morphological changes of rat small intestine after short-time exposure to concavalin A or wheat germ agglutinin. Cell Struct Funct 1986; 11: 285-93.

31 King TP, Pusztai A, Grant G, Slater D. Immunogold localization of ingested kidney bean (Phaseolus vulgaris) lectins in epithelial cells of the rat small intestine. Histochem f 1986; 18: 413-20.

32 Leavitt RD, Felsted RL, Bachur NR. Biological and biochemical properties of Phaseolus vulgaris isolectins. F Biol Chem 1977; 252: 2961-6.

33 Koninkx JFJG, Hendriks HGCJM, van Rossum JMA, Van den Ingh TSGAM, Nouwen JMVM. Interaction of den Ingh TSGAM, Nouwen JMVins with the cellular metabolism of differentilegume lectins with the cellular metabolism of differenti-
ated Caco-2 cells. Gastroenterology 1992; 102: 1516-23. 